\title{
Large multistate outbreak of norovirus gastroenteritis associated with frozen strawberries, Germany, 2012
}

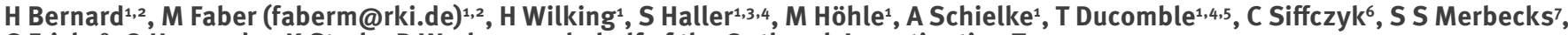

G Fricke ${ }^{8}, 0$ Hamouda $^{1}$, K Stark ${ }^{1}$, D Werber ${ }^{1}$, on behalf of the Outbreak Investigation Team 9

1. Robert Koch Institute, Berlin, Germany

2. These authors contributed equally

3. Postgraduate Training for Applied Epidemiology, Berlin, Germany

4. European Programme for Intervention Epidemiology, Stockholm, Sweden

5. European Centre for Disease Prevention and Control, Stockholm, Sweden

6. State Health Authority Brandenburg, Zossen, Germany

7. State Health Authority Saxony, Chemnitz, Germany

8. Federal Office of Consumer Protection and Food Safety, Berlin, Germany

9. The team members are listed at the end of the manuscript

Citation style for this article:
Bernard H, Faber M, Wilking H, Haller S, Höhle M, Schielke A, Ducomble T, Siffczyk C, Merbecks SS, Fricke G, Hamouda O, Stark K, Werber D, on behalf of the Outbreak Investigation Team. Large multistate outbreak of norovirus gastroenteritis associated with frozen strawberries, Germany, 2012. Euro Surveill. the Outbreak Investigation Team. Large multistate outbreak of norovirus gastroenteritis associated with frozen
2014;19(8):pii=20719. Available online: http://www.eurosurveillance.org/ViewArticle.aspx?Articleld=20719

Article submitted on 24 January 2013 / published on 27 February 2014

From 20 September through 5 October 2012, the largest recorded food-borne outbreak in Germany occurred. Norovirus was identified as the causative agent. We conducted four analytical epidemiological studies, two case-control studies and two surveys (in total 150 cases) in secondary schools in three different federal states. Overall, 390 institutions in five federal states reported nearly 11,000 cases of gastroenteritis. They were predominantly schools and childcare facilities and were supplied almost exclusively by one large catering company. The analytical epidemiological studies consistently identified dishes containing strawberries as the most likely vehicle, with estimated odds ratios ranging from 2.6 to 45.4 . The dishes had been prepared in different regional kitchens of the catering company and were served in the schools two days before the peaks of the respective outbreaks. All affected institutions had received strawberries of one lot, imported frozen from China. The outbreak vehicle was identified within a week, which led to a timely recall and prevented more than half of the lot from reaching the consumer. This outbreak exemplifies the risk of large outbreaks in the era of global food trade. It underlines the importance of timely surveillance and epidemiological outbreak investigations for food safety.

\section{Introduction}

Infection with norovirus is the most common cause of acute infectious gastroenteritis in European countries $[1,2]$, usually manifesting with self-limiting symptoms of vomiting and diarrhoea, with sudden onset and short duration [3]. Large protracted outbreaks of norovirus gastroenteritis are often recognised in institutions such as hospitals and homes for the elderly [4], with person-to-person transmission predominating.
Food-borne norovirus outbreaks are common, but still under-recognised $[5,6]$.

In Germany, outbreaks of acute infectious gastroenteritis are notifiable to the local public health departments according to the Protection Against Infection Act of 2001. The health departments conduct epidemiological investigations and take control measures. They also transmit outbreak information electronically to the public health authority of the respective federal state and, subsequently, to the Robert Koch Institute (RKI) on the national level [7]. On request of the state health authorities, the RKI assists in outbreak investigations, including analytical epidemiological studies.

On mid-day of 27 September 2012, the public health authority of the federal state of Brandenburg informed the RKI about several outbreaks of gastroenteritis in schools and childcare facilities in Brandenburg amassing to at least 500 cases. Diarrhoea or vomiting in affected individuals had started on the evening before. All affected institutions offered lunch provided by Caterer $\mathrm{X}$, a company operating across Germany, and a food-borne outbreak was suspected. According to the public health department of one of the affected counties, Caterer $\mathrm{X}$ was already aware of gastroenteritis cases in four other German federal states (Berlin, Saxony-Anhalt, Saxony and Thuringia). The RKI informed the two national food safety authorities, the Federal Institute for Risk Assessment (BfR) and the Federal Office of Consumer Protection and Food Safety (BVL), and the public health authorities of the other 15 federal states about the situation and requested information on similar outbreaks. By the evening of the same day, the RKI had knowledge of more than 4,000 cases relating to outbreaks in schools and childcare 
facilities supplied by Caterer $\mathrm{X}$ in four neighbouring federal states in the east of Germany.

This report focusses on the epidemiological investigations to identify the outbreak vehicle and to prevent further cases. Details of the laboratory investigations are presented elsewhere [8].

\section{Methods}

\section{Descriptive analysis}

In daily teleconferences, the public health authorities of the affected federal states and the RKI exchanged information on the number of affected institutions (including aggregated case numbers) and on laboratory results from human samples taken in the context of the outbreak. For the descriptive analysis, we defined a case as a person with diarrhoea or vomiting from 19 September through 7 October 2012, who did not test positive for any pathogen other than norovirus and who attended an affected institution. An institution was considered to be affected if it offered meals by any external caterer and if at least 10 cases had occurred in that institution (or, in small institutions, if $10 \%$ of persons were cases). We did not restrict affected institutions to those supplied by Caterer $\mathrm{X}$ to remain sensitive to the potential involvement of other caterers in this outbreak.

\section{Analytical studies}

On the individual level we conducted two case-control studies (CCS) and two surveys in affected secondary schools in three federal states. For the CCS, we interviewed pupils directly at their schools, for the surveys, a web-based (Survey 1) and an email (Survey 2) questionnaire were used. Exposure histories were recorded for menu items offered in these schools for lunch (as listed on weekly menu plans) and other food items available in the school, e.g. in the cafeteria. The canteens of all four schools had been supplied by different regional kitchens of Caterer $\mathrm{X}$.

The causative agent was unknown at the start of all four studies, but was suspected to be norovirus or bacterial toxins, based on reported symptoms and the sudden and almost simultaneous occurrence of disease within the institutions. Thus, the relevant period of exposure was considered to be the three days before the start of the outbreaks in these institutions (the dates were not identical at the four study sites). In all four studies, we investigated whether eating at the school canteen was associated with illness. We restricted the calculation of food-specific associations to individuals who reported having had lunch at the school canteen on any of the days of the exposure period. Pupils who reported gastroenteric illness in the family in the week before the outbreak period were excluded from the analysis because they could have been secondary cases of illness in their household. We compared cases and controls regarding their food exposures, calculated odds ratios (ORs) and 95\% confidence intervals ( $\mathrm{Cl}$ ), and assessed statistical significance using Fisher's exact or other appropriate tests. If several food items were associated with disease in univariable analyses with an $O R>1, a p$ value $<0.2$ and an exposure reported by at least $25 \%$ of cases, multivariable logistic regression analysis (exact method for the surveys) was performed with a manual forward selection of variables (cut-off: p 0.2 ). Statistical analyses were conducted in $R$ [9] for the CCS and Stata [10] for the surveys.

\section{Case-control study 1}

CCS1 was conducted on 1 and 2 October in School A in a city in Saxony. The school had experienced a sudden surge of gastroenteritis cases during calendar week 39 (24-30 September) with a peak on Wednesday, 26 September, and had been closed on 28 September due to the outbreak.

We restricted the study to pupils from grades 5 to 7 (10-13 year-olds) because these age groups were predominantly affected in this school. We defined a case as a pupil with onset of vomiting or diarrhoea from 24 to 30 September (outbreak period for $\mathrm{CCS}_{1}$ ). Of the approximately 70 cases, we selected two thirds for the study using systematic random sampling. Eligible controls were all pupils from three school classes who did not report vomiting or diarrhoea during the outbreak period. The classes were arbitrarily chosen by the deputy head of the school. Assuming an exposure prevalence of $70 \%$ among cases, a case-to-control ratio of 1 would have allowed us to detect an OR of 4 with a power of $86 \%$ at a significance level of $5 \%$.

We collected information on the participants' age and sex, symptoms, date of symptom onset and on food exposures at the school's canteen during calendar week 39, as indicated by the canteen's menu plan, which listed four meal choices daily. For data entry and immediate univariable analysis on site, we used the Linelist tool, a spreadsheet file developed at the RKI, to assist in the epidemiologic investigation of local outbreaks [11].

On 2 October, we conducted a sub-study restricting the study population to those who had reported eating at the school canteen on Monday 24 September. Cases with symptom onset after 28 September were excluded from the analysis. In this sub-study, participants were explicitly asked for the consumption of strawberry compote because it had not only been part of one main meal but also been offered as a dessert with two of the other three meal choices. The information was collected in an aggregate fashion during a congregation of cases and controls in the school auditorium, by sending each pupil to one of four corners depending on the pupils' outcome and exposure status (a live $2 \times 2$ table). The children were first split into two groups based on presence of symptoms, and these groups were divided further based on their recollection of having eaten strawberries. Pupils were explicitly told not 
to walk with their friends, but according to their recollection of symptoms and food consumption.

Case-control study 2

CCS2 was conducted on 4 October in School B in the state of Thuringia. The school had not been closed in response to the outbreak. The aim of the study was to investigate whether the results of CCS1 were reproducible in a different geographical region. The methodology was identical to CCS1 with the following exceptions: Pupils from grade 8 (14 years-old) were additionally included, the outbreak period was from 24 through 27 September, and eligible controls came from five arbitrarily chosen classes. Because strawberry compote was offered as dessert with several meal choices, even on the same day, we asked for this food item in an additional question.

Survey 1 (web-based questionnaire)

This study was conducted at School C located in Saxony using an online questionnaire. The school had experienced a sudden surge of gastroenteritis cases during the last two weeks of September and, in response to the outbreak, had been closed on Friday 28 September. Lunches consisted of a main component (e.g. chicken wings), pre-ordered by the pupils and dispensed by canteen staff, and side dishes, salads and desserts for a self-service buffet cart.

Study participants were recruited through a letter, distributed by teachers and addressed to the parents of all pupils of grades 5 to $8(n=451)$ present at the school on 5 October. It informed about the aims of the study and invited participation in an online survey. The questionnaire was accessible (password-protected) from 5 October through 8 October. It contained questions on demography (age, sex, grade), potential disease history (symptoms, time course) and food exposure history from 20 through 27 September (choice of three main components and around 10 sides and desserts daily). We defined a case as a pupil with onset of vomiting or diarrhoea from 20 through 29 September. Cases with an onset date 20-23, 24-26 and 27-29 September were defined as first-, second- and thirdwave cases, respectively.

Survey 2 (email questionnaire)

This study was conducted at School D in Berlin. On 5 October, 38 cases of gastroenteritis had been notified to the local health department by the head of the school. Because school holidays had just begun at the start of the study, face-to-face interviews were not feasible. We therefore developed a questionnaire covering, in addition to demographic and symptom information, meals served between 24 and 28 September (choice of four dishes daily plus salad buffet). This questionnaire was emailed to the parents of all pupils under the age of 18 years (approximately $n=900$ ). Questionnaires could be returned to the RKI via electronic or regular mail between 1 and 5 October. Cases were defined as pupils with onset of diarrhoea and/or vomiting from 24 through 28 September.

Food trace-back investigations

The German Task Force on Food and Feed safety, consisting of food safety authorities of affected states and at the national level, convened on 29 September. The task force coordinated food safety investigations, which also included epidemiological product tracing investigations.

\section{Results}

\section{Descriptive analysis}

A total of 390 institutions in five federal states in East Germany were reported as affected during the outbreak period. The earliest outbreak in an institution started on 20 September, the latest on 5 October, and most started between 25 and 28 September with a peak on 27 September ( $n=108$ institutions, $28 \%$ ) (Figure 1). A median of 21 children were affected per institution (inter-quartile range (IQR): 12-37).

The majority of affected institutions were schools (244/390, 63\%) and childcare facilities (140/390, 36\%), three were facilities for disability care, two were homes for the elderly and one was a rehabilitation clinic.

A total of 10,950 persons, mostly children and teenagers but also staff members, were reported ill in the affected institutions. The median proportion of cases among regular attendees was $14 \%$ (IQR: 10-22) across all affected institutions, and 18\% (IQR: 12-27) in childcare facilities. At least $38(0.3 \%)$ people required hospitalisation; the majority of illnesses were of short duration and self-limiting. Figure 2 shows the incidence of illnesses among persons under the age of 18 years by district. The federal states of Saxony, Brandenburg and Berlin were predominantly affected, which also reflects the distribution of affected institutions $(n=130$, 129 and 88 , respectively).

\section{FIGURE 1}

Number of affected institutions by date of onset of first case in the respective institution, multistate outbreak of norovirus gastroenteritis, Germany, $2012\left(n=309^{a}\right)$

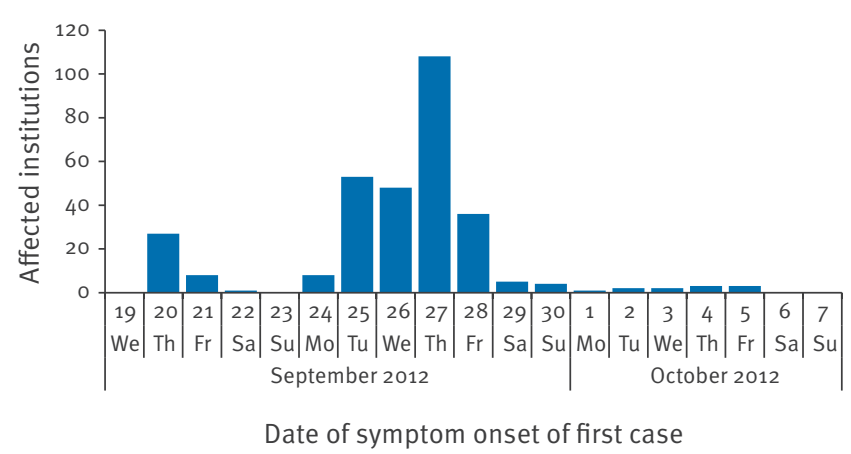

a Date of onset of first case was available for 309 institutions. 
As of 8 October 2012, 555 human specimens (339 from ill persons, and a convenience sample of 216 staff members of Caterer $\mathrm{X}$ with unknown disease status) were reported by the health authorities of four of the five affected federal states. Of those, $32 \%$ were positive for norovirus ( $40 \%$ of ill persons, $20 \%$ of staff members). No other viral or bacterial pathogens or bacterial toxins were reported from the respective health departments in connection with the outbreak.

\section{Analytical studies}

All four analytical studies, comprising 150 cases and 274 controls, identified dishes containing strawberries as vehicles of infection (either strawberry compote or strawberry fruit quark) (Table).
Case-control study 1

We included 43 cases and 54 controls (median age for each: 11 years), three potential secondary household cases were excluded. Symptom onset was from 24 through 30 September, with a steep increase and a peak of the epidemic curve on Wednesday 26 September ( $n=16$ cases) suggesting a point source (Figure 3A).

Most cases, and a higher proportion of cases than controls, had eaten at the school's canteen on Monday 24 and Tuesday 25 September (see Table), but not on the following two days (when a substantial proportion of cases were already sick). The only dish offered on one of these two days that was positively associated

\section{FIGURE 2}

Cases per 100,000 population under the age of 18 years by districts, and locations of analytical study sites, multistate outbreak of norovirus gastroenteritis, Germany, $2012(n=10,950)$

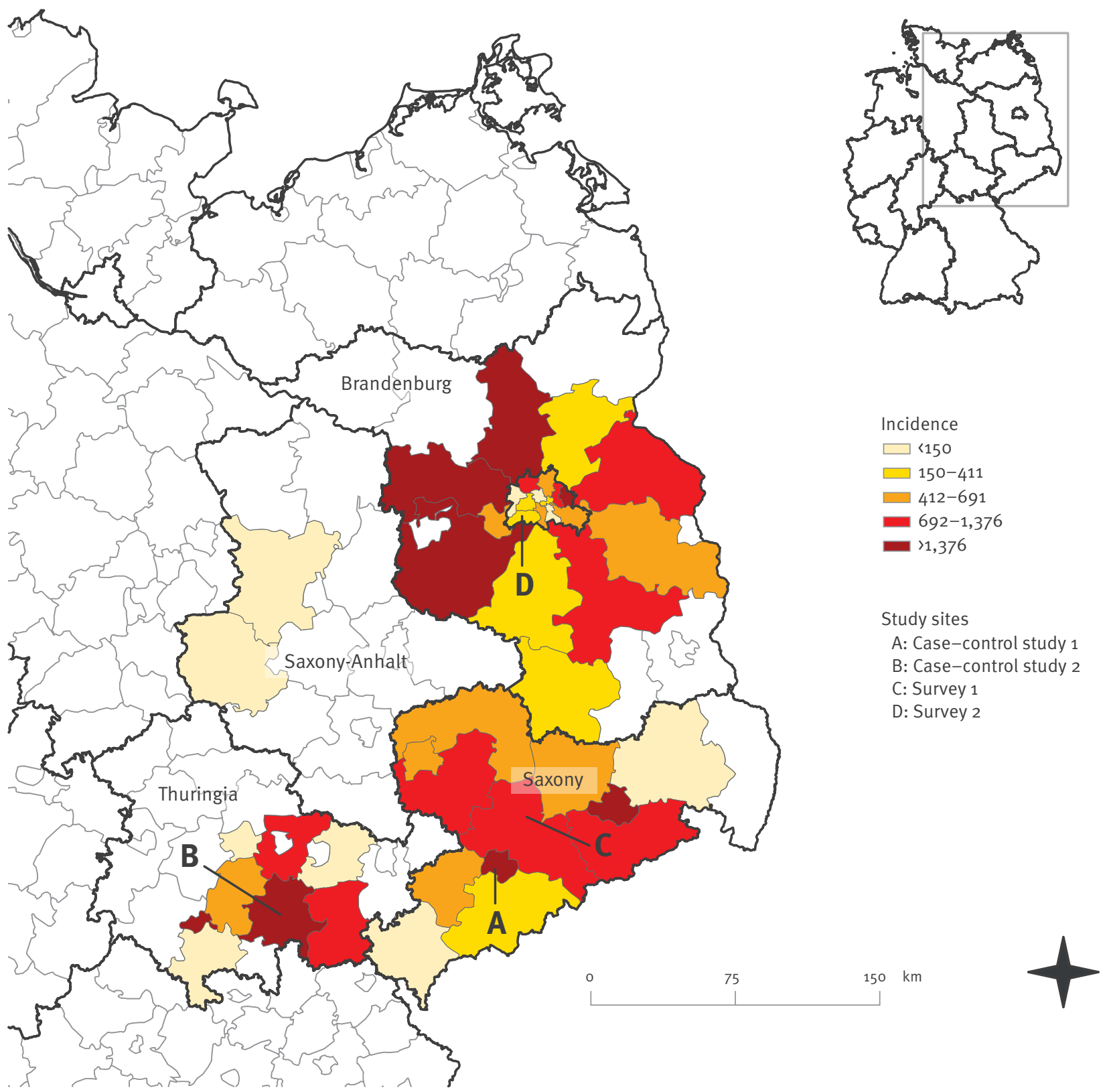




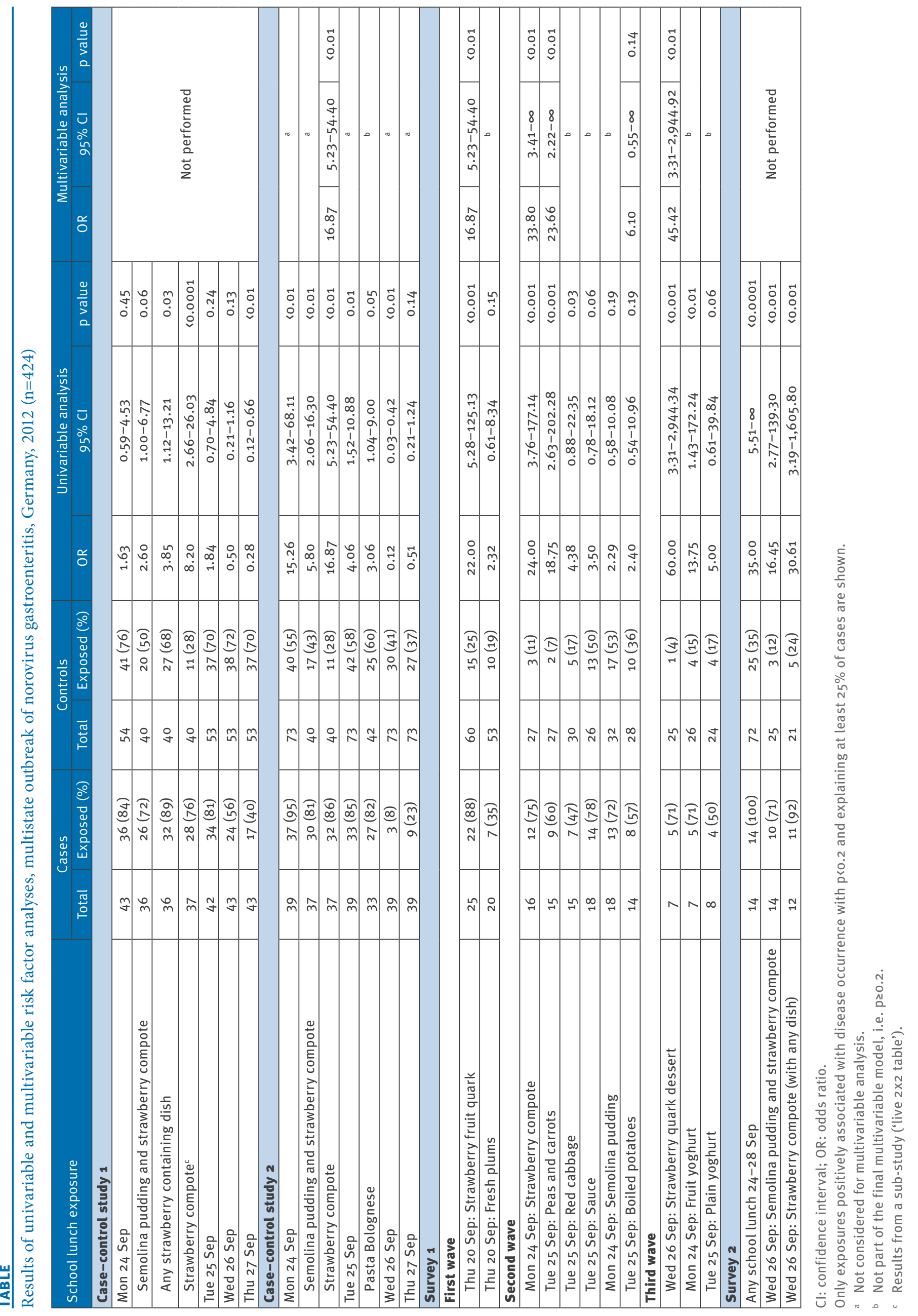


with illness with a $p$ value $<0.1$, was semolina pudding, which had been served on Monday with a choice of cherries, sugar and cinnamon, or cold strawberry compote (Table).

Of the 36 cases, 26 reported to have chosen the semolina pudding. However, on that day strawberry compote had been offered with three of the four meal choices. We therefore compared cases and controls regarding the choice of any meal containing strawberry compote. Cases had chosen significantly ( $p<0.05)$ more often a strawberry compote-containing dish than controls. In the sub-study including those who had eaten at the canteen on Monday 24 September, 28 of 37 cases but only 11 of 40 controls reported to have eaten strawberry compote $(\mathrm{OR}=8.20 ; 95 \% \mathrm{Cl}: 2.66-26.03 ; \mathrm{p}<0.01)$.

Having identified a dish served on Monday 24 September as the likely vehicle of infection, we estimated a median incubation period of two days (IQR: 2-6 days; onset data only available by full days).

\section{FIGURE 3}

Time course of the norovirus outbreak: number of cases included in the four analytical studies, by date of symptom onset, Germany, $2012(\mathrm{n}=148)$

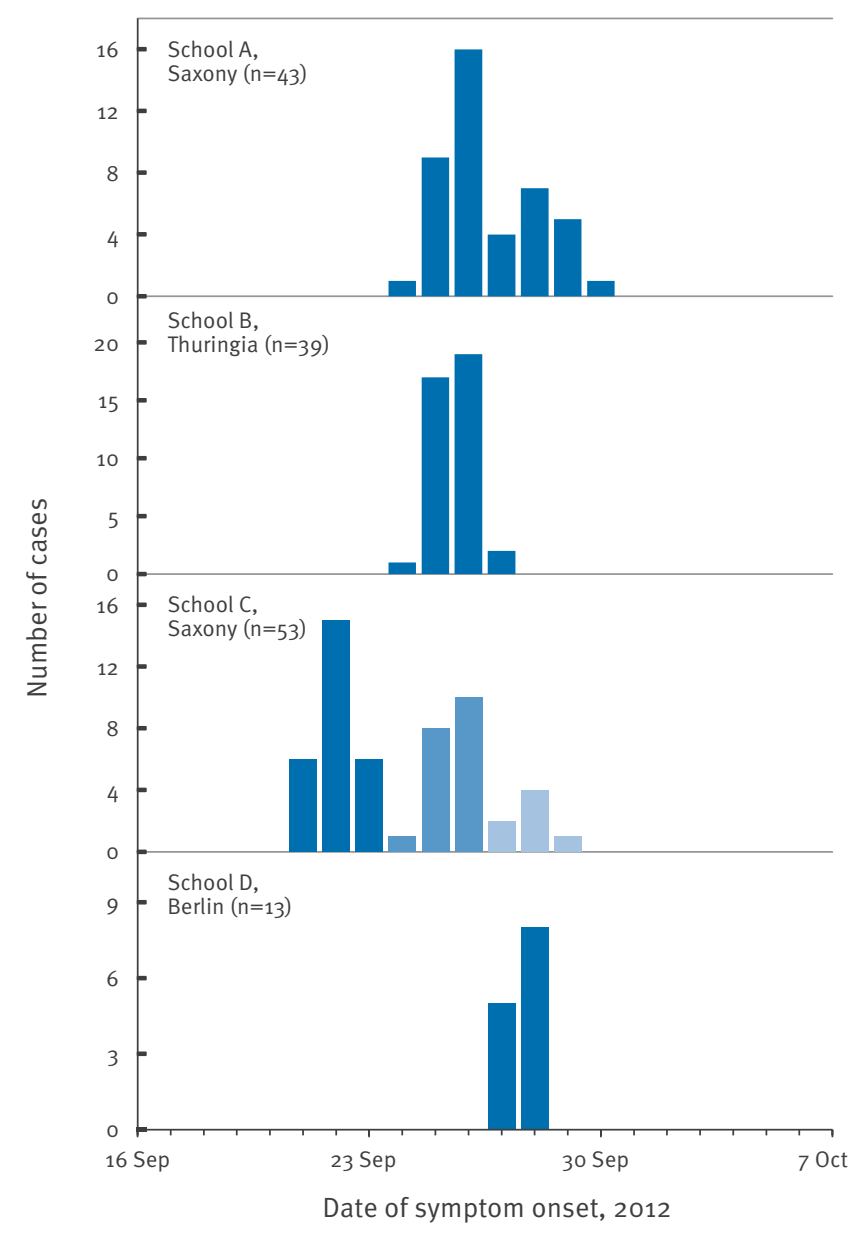

The columns for School C are filled with different colours for the three waves of disease (see case definition).
Case-control study 2

We included 39 cases and 73 controls in the analysis (median age: 11 and 12 years, respectively), excluding again three potential household secondary cases. The epidemic curve showed an even steeper increase in case numbers with 36 of 39 of cases with symptom onset on Tuesday $25(n=17)$ or Wednesday $26(n=19)$ September (Figure 3B).

Most cases, and a higher proportion of cases than controls, had eaten at the school's canteen on Monday 24 and Tuesday 25 September (see Table), but not on the following two days (when a substantial proportion of cases were already sick). On both days, the consumption of one dish was significantly associated with illness: semolina pudding with strawberry compote, sugar and cinnamon on Monday, and pasta with Bolognese sauce on Tuesday (Table). Again, the strawberry compote had been offered with two of the four dishes on Monday, and the association between consumption and illness was even stronger when analysing compote as a separate variable. In multivariable analyses including the exposure variables strawberry compote on Monday and pasta on Tuesday, only the consumption of strawberry compote remained significantly associated with illness $(\mathrm{OR}=16.87 ; 95 \% \mathrm{Cl}$ : 5.23-54.4; p<0.01).

Survey 1 (web-based questionnaire)

We included 54 cases and 75 controls (median age of each: 12 years) in the analysis (participation rate: $29 \%$ ). The epidemic curve showed three peaks of dates of symptom onset (Figure $3 \mathrm{C}$ ). Overall, the proportion of persons having had lunch at the school canteen from 20 through 27 September was significantly higher in cases than in controls ( $98 \%$ vs $76 \%, O R=16.7 ; 95 \%$ Cl: 2.4-710.1; $p<0.01)$.

In univariable analyses (Table) we found an association between being a case in the first wave and the consumption of strawberry quark and fresh plums both served on 20 September. In the multivariable analysis, only the former remained statistically significant (OR=27.13; 95\% Cl: 5.24-276.40; p<0.01).

For the cases in the second wave, we found a significant association with having eaten at the school canteen on 24 September (multivariable analysis: $O R=11.1$; $95 \% \mathrm{Cl}: 1.38-88.4 ; \mathrm{p}<0.05)$. Of the 35 items served on that and the following day, six were associated with disease and included in the multivariable analysis, in which strawberry compote $(\mathrm{OR}=33.80 ; 95 \% \mathrm{Cl}$ : $3.41-$ $\infty$; $\mathrm{p}<0.01)$ and carrots and peas $(\mathrm{OR}=23.66 ; 95 \% \mathrm{Cl}$ :

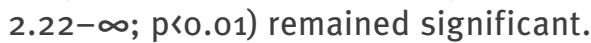

For cases in the third wave, the univariable analysis showed three different food items to be associated with occurrence of disease. In the multivariable analysis only strawberry quark remained statistically significant $(\mathrm{OR}=45.42 ; 95 \% \mathrm{Cl}: 3.31-2,944.92 ; \mathrm{p}<0.01)$. 
Survey 2 (email questionnaire)

We received 86 completed questionnaires (response 10\%). 14 participants were classified as cases, 72 as controls. Median age of cases and controls was 12 years (range: 9-16 and 9-17, respectively). Onset times peaked on the afternoon of 27 September and the following morning (Figure 3D).

The proportion of persons having eaten at the school's canteen from 24 through 28 September was significantly higher in cases than in controls. Of all dishes on offer during that period, only semolina pudding with strawberry compote resulted in a statistically significant positive association with disease in the univariable analysis (Table). Strawberry compote was also offered as a dessert alongside China vegetables, but only one pupil reported to have chosen this dish. The strongest association was found when asking specifically for the consumption of strawberry compote (independent of main course). The median incubation period, calculated from the most likely time of exposure to strawberries (13:00 on 26 September) and the individual times of symptom onset, was 35 hours (range: $12-40$ hours).

Food trace-back investigations

Frozen strawberries had been used in regional kitchens of Caterer X. They were part of a lot of 22 tonnes imported by Company $Y$ in Saxony from a company in China, packaged in 2,201 boxes of $10 \mathrm{~kg}$ each. Of the institutions with available information, 98\% (368/377) were supplied by regional kitchens of Caterer $\mathrm{X}$, the remainder were supplied by two smaller catering companies. All three caterers were supplied by the same company (Company Y). All affected institutions had received products containing the implicated frozen strawberries. Starting on 5 October, the date of a joint press release by RKI, BfR and BVL, Company $Y$ began withdrawing the lot of frozen strawberries from their customers (the company had already stopped further delivery of the strawberries before that date). Overall, delivery stop and recall ensured that at least 1,136 boxes (more than 11 tons) of strawberries from the incriminated lot did not reach the consumer. The remaining 1,065 boxes (ca 10.7 tons) had either already been used or were destroyed under the supervision of the local food safety authorities after the recall. On Oct 8, Saxony's State Health Laboratory detected norovirus in a sample obtained from an unopened box of the incriminated lot of frozen strawberries [12].

\section{Discussion}

We report here the largest recorded food-borne outbreak in Germany. It affected several hundreds of institutions supplied almost exclusively by one large caterer and was associated with strawberries imported frozen in a large lot from China. Norovirus was identified as the causative agent. Although the individual clinical courses of disease were mild, the overall disease burden was considerable. The high number of cases caused substantial distress and impairment of the daily routine in affected institutions and families, considerable concerns about food safety in canteens for children, and nationwide media interest.

The epidemiological studies provided strong evidence for strawberries as the vehicle of infection. Conducted in different geographical regions and using various designs, they consistently and exclusively showed statistically significant associations between illness and the consumption of strawberry dishes. Furthermore, in all studies, affected institutions offered strawberry dishes two calendar days before the peak of illnesses, and in one instance, several strawberry-containing dishes, served on different days, caused several waves of illnesses.

Epidemiological evidence guided food safety investigations on the local, state and national level [12]. Early identification of the vehicle of infection led to a timely withdrawal of more than half of the lot. Assuming a similar level of contamination in the part of the lot that was withdrawn, at least 11,000 cases were averted by the withdrawal, probably even more, seeing as only a fraction of the delivered strawberries had been prepared for consumption. According to the report of the German Task Force on Food and Feed Safety, some of the involved regional kitchens of Caterer $\mathrm{X}$ reported not to have heated the strawberries during preparation of the implicated dishes whereas others stated that they had, which may in part explain that not all institutions supplied by the involved regional kitchens reported cases of gastroenteritis [12].In response to this outbreak, recommendations in Germany for institutions catering for vulnerable populations (including schools and child care facilities) have been amended and now specifically include the advice to heat frozen berries [13]. Furthermore, from 1 January 2013, a European Union (EU) regulation requires $5 \%$ of consignments of frozen strawberries imported from China into the EU to be tested for norovirus [14].

Infectious disease outbreaks due to contaminated produce have gained importance in the recent past [15], including norovirus outbreaks in Europe linked to frozen raspberries [16-22] or blackberries [23] and the multistate outbreak of hepatitis A due to mixed frozen berries [24]. Also strawberries have repeatedly been incriminated in large hepatitis A outbreaks in the United States [25,26] and in Europe [27]. Germany has recently faced a number of outbreaks caused by contaminated vegetables or fruits including sprouts and watermelons [28-30]. The original contamination of the food vehicles or relevant ingredients occurred in countries that were not known to be affected by outbreaks, which complicated or even prevented thorough source investigations. In none of these outbreaks, including this one, was the mode of contamination elucidated. Undoubtedly, transnational source investigations pose particular challenges [31]; political and economic issues may sometimes hamper effective collaboration. A better understanding of how the berries 
became contaminated is crucial for developing longterm prevention measures upstream of the retailer. Several different norovirus genotypes of genogroups I and II were detected in the strawberries [8] (and also in human samples) [32]. Together with the large scale of the outbreak, this lends support to the hypothesis that the use of contaminated water in the production of the strawberries was responsible for the outbreak.

This report exemplifies the risk of large outbreaks in the era of global food trade. Today, unprecedented volumes of produce (here 22 tonnes) are distributed to a large number of markets throughout the world [33], thereby increasing the risk for food safety. Public health surveillance needs to adapt to these challenges, e.g. be able to detect outbreaks caused by widely disseminated foods. Surveillance using molecular subtyping information allows establishing links between disease occurrences in different regions, usually seemingly sporadic cases or small clusters [34]. The outbreak described here appeared as an accumulation of concurrent local outbreaks in several adjacent states. Thus, in addition to molecular surveillance, rapid communication of local outbreaks to the state level, as it happened in the outbreak-detecting state of Brandenburg, enables rapid recognition and investigation of supra-regional events even before the aetiology is known, and should be implemented in routine infectious disease surveillance.

\section{Outbreak Investigation Team}

Mona Askar, Barbara Gunsenheimer-Bartmeyer, Susanne Behnke, Janina Breidenbach, Lena Fiebig, Andreas Gilsdorf, Benedikt Greutélaers, Jane Hecht, Julia Hermes, Franziska Jentsch, Astrid Milde-Busch, Karina Preußel, Maximilian Prohl, Cornelius Remschmidt, Sabine Ritter, Bettina Rosner, Claudia Santos-Hövener, Lars Schaade, Madlen Schütze, Kristin Tolksdorf, Matthias Wetzstein (Robert Koch Institute, Berlin, Germany);

Jörg Bätzing-Feigenbaum (Berlin State Office for Health \& Social Affairs, Berlin, Germany);

Hanna Oppermann (Agency for Consumer Protection of the Federal State of Saxony-Anhalt, Magdeburg, Germany); Anke Popp (Thuringian State Authority for Consumer Protection, Bad Langensalza, Germany).

\section{Acknowledgements}

We thank the staff of local and state health departments for collecting the data that were the basis of the descriptive analysis. For their support of the analytical studies we would like to thank the parent representative of school D, the staff of the Local Health Department Steglitz-Zehlendorf, and the Local Veterinary Authority Chemnitz. Furthermore we would like to acknowledge the help of other colleagues in the Department for Infectious Disease Epidemiology and the Press Department at the RKI during the acute phase of the outbreak, and PAE/EPIET coordinators. Last but not least, we would like to thank all study participants, the staff and the heads of the participating schools for their support. No funding was received for the presented work.
Conflict of interest

None declared.

Authors' contributions

$\mathrm{HB}, \mathrm{MF}, \mathrm{HW}$ and DW drafted the manuscript. HB and DW were the principle investigators of CCS 1 , DW of CCS 2, MF of Survey 1 , and SH of Survey 2 (all substantially contributed to conception and design, data collection, analysis and interpretation). HB designed the tool used for data collection and analysis in CCS 1 and 2 and represented the RKI at the Task Force Gastroenteritis collaborating with the food safety authorities. HW was responsible for the collection, analysis and interpretation of descriptive data. $\mathrm{MH}$ performed the data analysis of CCS 1 and 2. AS substantially contributed to data interpretation and represented the RKI at the Task Force Gastroenteritis. TD participated in data collection of CCS 1 and was a principle investigator of CCS 2 (data collection and interpretation). CS was a principle investigator for the State Health Authority Brandenburg (collection, analysis and interpretation of descriptive data). SSM was a principle investigator for the State Health Authority Saxony (collection, analysis and interpretation of descriptive data) and contributed to the conception of CCS 1. GF coordinated the German Task Force on Food and Feed Safety. OH and KS substantially contributed to the interpretation of descriptive and study data. All authors critically revised the manuscript and approved of the final version.

\section{References}

1. Phillips G, Tam CC, Conti S, Rodrigues LC, Brown D, IturrizaGomara M, et al. Community incidence of norovirus-associated infectious intestinal disease in England: improved estimates using viral load for norovirus diagnosis. Am J Epidemiol. 2010;171(9):1014-22. http://dx.doi.org/10.1093/aje/kwq021

2. Verhoef L, Koopmans M, van Pelt W, Duizer E, Haagsma J, Werber D, et al. The estimated disease burden of norovirus in The Netherlands. Epidemiol Infect. 2013:141(3):496-506. http://dx.doi.org/10.1017/So950268812000799

3. Glass RI, Parashar UD, Estes MK. Norovirus gastroenteritis. N Engl J Med. 2009;361(18):1776-85. http://dx.doi.org/10.1056/ NEJMrao804575

4. Matthews JE, Dickey BW, Miller RD, Felzer JR, Dawson BP, Lee AS, et al. The epidemiology of published norovirus outbreaks: a review of risk factors associated with attack rate and genogroup. Epidemiol Infect. 2012;140(7):1161-72. http:// dx.doi.org/10.1017/So950268812000234

5. Hall AJ, Eisenbart VG, Etingue AL, Gould LH, Lopman BA, Parashar UD. Epidemiology of foodborne norovirus outbreaks, United States, 2001-2008. Emerg Infect Dis. 2012;18(10):1566 73. http://dx.doi.org/10.3201/eid1810.120833

6. Scallan E, Hoekstra RM, Angulo FJ, Tauxe RV, Widdowson MA, Roy SL, et al. Foodborne illness acquired in the United States -major pathogens. Emerg Infect Dis. 2011;17(1):7-15. http:// dx.doi.org/10.3201/eid1701.P11101

7. Niemer U. [The new Protection against Infection Act]. Gesundheitswesen. 2001;63 Suppl 2:S136-8. German. http:// dx.doi.org/10.1055/s-2001-16628

8. Mäde D, Trübner K, Neubert E, Höhne M, Johne R. Detection and Typing of Norovirus from Frozen Strawberries Involved in a Large-Scale Gastroenteritis Outbreak in Germany. Food Environ Virol. 2013;5:162-8. http://dx.doi.org/10.1007/ S12560-013-9118-0

9. R Core Team. R: A Language and Environment for Statistical Computing. Vienna: R foundation for Statistical Computing; 2012. ISBN 3-900051-07-0. Available from: http://www.Rproject.org/

10. Stata Corp. Stata Statistical Software: Release 12. College Station: StataCorp LP; 2011. Available from: http://www.stata. com/

11. Werber D, Bernard H: Reducing the barriers against analytica epidemiological studies in investigations of local foodborne disease outbreaks in Germany - a starter kit for local health authorities. Euro Surveill. 2014;19(8): pii=20714.

12. Task Force Gastroenteritis: Activity report by the Task Force on Food and Feed Safety in identifying the food-related sources 
of the gastroenteritis outbreak in Germany. Braunschweig: Federal Office of Consumer Protection and Food Safety (BVL); 2012. Available from: http://www.bvl.bund.de/SharedDocs/ Downloads/01_Lebensmittel/Task_Force/Task_Force_ Gastroenteritis_Activity_Report.html

13. Bundesinstitut für Risikobewertung (BfR). Sicher verpflegt. Besonders empfindliche Personengruppen in Gemeinschaftseinrichtungen. [Safe care. Particularly vulnerable groups in community facilities]. Berlin: BfR; 2013. German. Available from: http://www.bfr.bund.de/cm/350/ sicher-verpflegt-besonders-empfindliche-personengruppen-ingemeinschaftseinrichtungen.pdf

14. European Union. Commision Implementing Regulation (EU) No $1235 / 2012$ amending Annex I to Regulation (EC) No 669/2009 implementing Regulation (EC) No 882/2004 of the European Parliament and of the Council as regards the increased level of official controls on imports of certain feed and food of non-animal origin. In: Union E, editor. Brussels; 2012. p. L 350/44-50.

15. Lynch MF, Tauxe RV, Hedberg CW. The growing burden of foodborne outbreaks due to contaminated fresh produce: risks and opportunities. Epidemiol Infect. 2009;137(3):307-15. http://dx.doi.org/10.1017/So950268808001969

16. Le Guyader FS, Mittelholzer C, Haugarreau L, Hedlund KO, Alsterlund R, Pommepuy M, et al. Detection of noroviruses in raspberries associated with a gastroenteritis outbreak. Int J Food Microbiol. 2004;97(2):179-86. http://dx.doi.org/10.1016/j. ijfoodmicro.2004.04.018

17. Cotterelle B, Drougard C, Rolland J, Becamel M, Boudon M, Pinede $S$, et al. Outbreak of norovirus infection associated with the consumption of frozen raspberries, France, March 2005. Euro Surveill. 2005;10(17):pii=2690.

18. Falkenhorst G, Krusell L, Lisby M, Madsen SB, Bottiger $B$, Molbak K. Imported frozen raspberries cause a series of norovirus outbreaks in Denmark, 2005. Euro Surveill. 2005;10(38): $\mathrm{pii}=2795$.

19. Ponka A, Maunula L, von Bonsdorff $\mathrm{CH}$, Lyytikainen O. An outbreak of calicivirus associated with consumption of frozen raspberries. Epidemiol Infect. 1999;123(3):469-74. http:// dx.doi.org/10.1017/S0950268899003064

20. Hjertqvist M, Johansson A, Svensson N, Abom PE, Magnusson $C$, Olsson $M$, et al. Four outbreaks of norovirus gastroenteritis after consuming raspberries, Sweden, June-August 2006. Euro Surveill. 2006;1136): pii=3038.

21. Maunula L, Roivainen M, Keranen M, Makela S, Soderberg K, Summa M, et al. Detection of human norovirus from frozen raspberries in a cluster of gastroenteritis outbreaks. Euro Surveill. 2009;14(49): $\mathrm{pii}=19435$.

22. Sarvikivi E, Roivainen M, Maunula L, Niskanen T, Korhonen T, Lappalainen $M$, et al. Multiple norovirus outbreaks linked to imported frozen raspberries. Epidemiol Infect. 2012;140(2):260-7. http://dx.doi.org/10.1017/ So950268811000379

23. Fell G, Boyens M, Baumgarte S. [Frozen berries as a risk factor for outbreaks of norovirus gastroenteritis. Results of an outbreak investigation in the summer of 2005 in Hamburg]. Bundesgesundheitsblatt Gesundheitsforschung Gesundheitsschutz. 2007;50(2):230-6. German. http://dx.doi. org/10.1007/s00103-007-0142-9

24. European Centre for Disease Prevention and Control (ECDC). Rapid Outbreak Assessment. Update: Outbreak of hepatitis A virus infection in Italy and Ireland. Stockholm: ECDC; 2013. Available from: http://ecdc.europa.eu/en/publications/ publications/roa-update_hav_italy_ireland-final.pdf

25. Hutin YJ, Pool V, Cramer EH, Nainan OV, Weth J, Williams IT, et al. A multistate, foodborne outbreak of hepatitis A. National Hepatitis A Investigation Team. N Engl J Med. 1999;340(8):595602. http://dx.doi.org/10.1056/NEJM199902253400802

26. Niu MT, Polish LB, Robertson BH, Khanna BK, Woodruff BA, Shapiro CN, et al. Multistate outbreak of hepatitis A associated with frozen strawberries. J Infect Dis. 1992;166(3):518-24. http://dx.doi.org/10.1093/infdis/166.3.518

27. Nordic outbreak investigation team. Joint analysis by the Nordic countries of a hepatitis A outbreak, October 2012 to June 2013: frozen strawberries suspected. Euro Surveill. 2013;18(27):pii=20520.

28. Buchholz U, Bernard H, Werber D, Bohmer MM, Remschmidt C, Wilking $\mathrm{H}$, et al. German outbreak of Escherichia coli $0_{104}: \mathrm{H}_{4}$ associated with sprouts. N Engl J Med. 2011;365(19):1763-70. http://dx.doi.org/10.1056/NEJMoa1106482

29. Frank C, Werber D, Cramer JP, Askar M, Faber M, an der Heiden $M$, et al. Epidemic profile of Shiga-toxin-producing Escherichia coli $\mathrm{O}_{104}: \mathrm{H}_{4}$ outbreak in Germany. N Engl J Med. 2011;365(19):1771-80. http://dx.doi.org/10.1056/ NEJMoa1106483
30. Bayer C, Bernard H, Prager R, Rabsch W, Hiller P, Malorny B, et al. An outbreak of Salmonella Newport associated with mung bean sprouts in Germany and the Netherlands, October to November 2011. Euro Surveill. 2014;19(1):pii=20665.http:// dx.doi.org/10.2807/1560-7917.ES2014.19.1.20665

31. Tauxe RV, Hughes JM. International investigation of outbreaks of foodborne disease. BMJ. 1996;313(7065):1093-4. http:// dx.doi.org/10.1136/bmj.313.7065.1093

32. Robert Koch Institute. Großer Gastroenteritis-Ausbruch durch eine Charge mit Noroviren kontaminierter Tiefkühlerdbeeren in Kinderbetreuungseinrichtungen und Schulen in Ostdeutschland, $09-10 / 2012$. [Large outbreak of gastroenteritis casued by a batch of norovirus-contaminated frozen strawberries in child care institutions and schools in East Germany, 09-10/2012]. Epid Bull. 2012(41):414-7. German

33. Kimball AM, Arima Y, Hodges JR. Trade related infections: farther, faster, quieter. Global Health. 2005;1(1):3. http:// dx.doi.org/10.1186/1744-8603-1-3

34. Tauxe RV. Molecular subtyping and the transformation of public health. Foodborne Pathog Dis. 2006;3(1):4-8. http:// dx.doi.org/10.1089/fpd.2006.3.4 